\title{
One Versus Double Burr Holes for Treating Chronic Subdural Hematoma Meta-Analysis
}

\author{
Sirajeddin Belkhair, Gwynedd Pickett
}

\begin{abstract}
Objective and Design: There is controversy among neurosurgeons regarding whether double burr hole craniostomy (DBHC) is better than single burr hole craniostomy (SBHC) in the treatment of chronic subdural hematoma (CSH), in terms of having a lower revision rate. In order to compare the revision rates after SBHC versus DBHC, we performed a meta-analysis of the available studies in the literature. Materials and Methods: Multiple electronic health databases were searched to identify all the studies published between 1966 and December 2010 that compared SBHC and DBHC. Data were processed in Review Manager 5.0.18. Effect sizes were expressed in pooled odds ratio (OR) estimates, and due to heterogeneity between studies we used random effect of the inverse variance weighted method to perform the meta-analysis. Results: Five observational retrospective cohort studies were identified: four published studies and one unpublished, describing the outcomes of 355 DBHC and 358 SBHC to evacuate 713 CSH in 631 patients. Meta-analysis showed that there was no significant difference in the revision rates between double burr hole craniostomy and single burr hole craniostomy when performed to evacuate CSH. Pooled odds ratio for all the studies was 0.62 (95\% confidence interval $0.26-1.46)$. Conclusions: The results of this meta-analysis suggest that SBHC is as good as DBHC in evacuating chronic subdural hematoma and is not associated with a higher revision rate compared to DBHC.
\end{abstract}

RÉSUMÉ: Méta-analyse portant sur la supériorité de la craniostomie simple ou double dans le traitements l'hématome sous-dural chronique. Objectif et plan d'étude : Il existe une controverse chez les neurochirurgiens à savoir si la craniostomie double (CTD) est supérieure à la craniostomie simple (CTS) dans le traitement de l'hématome sous-dural chronique (HSDC), quant aux taux de réintervention. Nous avons effectué une méta-analyse des études publiées afin de comparer les taux de réintervention après la CTS et la CTD. Méthode : Nous avons recherché toutes les études publiées entre 1966 et décembre 2010 qui comparaient la CTS et la CTD dans plusieurs bases de données électroniques sur la santé. Les données ont été traitées au moyen de Review Manager 5.0.18. Les tailles d'effet ont été exprimées en termes d'estimés de rapports de cotes groupés et, à cause de l'hétérogénéité entre les études, nous avons utilisé un modèle aléatoire avec pondération par l'inverse de la variance pour effectuer la méta-analyse. Résultats : Cinq études rétrospectives d'observation de cohorte ont été identifiées : 4 études publiées et une étude non publiée décrivant les résultats de 355 CTD et de 358 CTS pour évacuer 713 HSDC chez 631 patients. La méta-analyse a montré qu'il n'y avait pas de différence significative dans le taux de réintervention entre la CTD et la CTS effectuée pour traiter une HSDC. Le rapport de cotes pour toutes les études était de 0,62 (intervalle de confiance à 95\% : 0,26 à 1,46). Conclusions : Les résultats de cette méta-analyse indiquent que la CTS est aussi efficace que la CTD pour évacuer un HSDC et n'est pas associée à un taux plus élevé de réintervention par rapport à la craniostomie CTD.

Can J Neurol Sci. 2013; 40: 56-60

Chronic subdural hematoma (CSH) is one of the most common surgical conditions treated by neurosurgeons ${ }^{1-5}$. The annual reported incidence of $\mathrm{CSH}$ is approximately $0.001-$ $0.002 \%{ }^{6}$; it is more common in the elderly population ${ }^{4}$ with the annual incidence rate in the elderly estimated at $0.0074 \%$. In 60 to $80 \%$ of cases of $\mathrm{CSH}$ a traumatic event is reported to precede the development of $\mathrm{CSH}$; the true figure may be higher as a mild traumatic event may not be recognized ${ }^{8}$.

Management options for chronic subdural hematoma include both surgical and non-surgical treatment ${ }^{2,3,9}$. Generally, nonsurgical management is considered for patients who are asymptomatic or present with mild headache, while surgical treatment is pursued for patients with neurological symptoms. Surgical evacuation of the CSH is achieved by draining the hematoma through various surgical techniques such as burr hole(s), twist drill evacuation, craniotomy, and endoscopicassisted evacuation of subdural collections. ${ }^{1-5}$.
Nowadays the most common surgical technique used to evacuate CSH is burr hole(s) craniostomy, considered by most neurosurgeons as the first tier treatment for $\mathrm{CSH}^{1,3-5,10}$. The number of burr holes (one versus two) that are required to drain $\mathrm{CSH}$ and to minimize the risk of recurrence of $\mathrm{CSH}$ remains controversial among neurosurgeons ${ }^{2,4,11}$. Many neurosurgeons prefer to treat $\mathrm{CSH}$ with $\mathrm{SBHC}$ as it is faster to perform, it in

From the Division of Neurosurgery, Dalhousie University, QE II Health Sciences Centre, Halifax, Nova Scotia, Canada.

Received April 30, 2012. Final Revisions Submitted July 27. 2012. Correspondence to: Sirajeddin Belkhair, QE II Health Sciences Centre, Halifax Infirmary, 3806 - 1796 Summer Street, Halifax, Nova Scotia, B3H 3A7, Canada. Email: sirajeeddin@hotmail.com. 
theory reduces the opportunity for surgical complications, and it is cosmetically better for the patients as it involves only one incision. However, other neurosurgeons believe that $\mathrm{SBHC}$ is not sufficient to evacuate $\mathrm{CSH}$, as it does not allow for irrigation between the holes, and that it risks a higher recurrence rate of CSH compared to DBHC.

There has been no previous systematic review that compared the revision rates of single versus double burr hole craniostomy. There have been a few observational studies that compared recurrence rates of single versus double burr holes craniostomy in the treatment of $\mathrm{CSH}^{2-4,11}$, but those studies have conflicting results. Post-operative recurrence of $\mathrm{CSH}$ requiring reoperation is a relatively infrequent but clinically significant complication after burr hole craniostomy ${ }^{2}$ and by providing systematic review of the available studies in the literature examining SBHC versus $\mathrm{DBHC}$, we aim to provide neurosurgeons with some evidencebased guidance in the treatment of patients with CSH. If one method is superior to the other in evacuating and/or preventing recurrence of $\mathrm{CSH}$, demonstrating this may save patients with $\mathrm{CSH}$ from requiring a second operation to evacuate recurrent or residual $\mathrm{CSH}$.

\section{Materials ANd Methods}

\section{Search strategy}

We searched multiple electronic health databases including MEDLINE (OvidSP), EMBASE (OvidSP), Cochrane Central Register of Controlled Trials, and Cochrane Database of Systematic Reviews, for all randomized and observational studies and for any previous systematic reviews published between 1966 and December 2010 that compared the recurrence rate of CSH after single and double burr holes craniostomy.

We used a keyword search mapped to subject headings (MeSH terms in Medline and EMTREE Thesaurus in EMBASE), then these subject headings were "exploded" using advance keyword searches to include all subtopics. We then included all the subheadings of those terms to provide the widest capture of most relevant studies. Terms used were (chronic subdural hematoma, craniotomy).

For a more inclusive search, we used text word search for the same keywords and for other terms not linked to subject headings (MeSH terms or EMTREE Thesaurus).

Terms used in text word search were (chronic subdural hematoma, subdural hematoma, subdural hemorrhage, burr hole, mini craniotomy and craniotomy). After using each keyword separately in the databases mentioned above, we combined keywords using the Boolean operator "OR" in two different concepts (chronic subdural hematoma and surgical treatment of $\mathrm{CSH}$ ) and then we combined search resulted from keywords of these two concepts using the Boolean operator "AND". The references listed in selected studies for this review were also searched for relevant studies. The search was then limited to studies published in the English language.

\section{Types of studies}

Any study (observational or randomized control trial) that compared the revision rates of $\mathrm{CSH}$ after SBHC and DBHC was considered. Studies that looked at the revision rate of $\mathrm{CSH}$ after either single or burr holes craniostomy without comparison to each other in the same population of patients were excluded.

\section{Type of outcome measures}

In this systemic review and meta-analysis, the outcome for each patient is categorical (whether or not patient required another surgery to evacuate $\mathrm{CSH}$ ), and the outcomes for the studies were the number of patients that required revision (required another operation) for $\mathrm{CSH}$ after being treated by single or double burr hole craniostomy.

\section{Inclusion criteria}

We included studies of ten patients or more with fewer than $10 \%$ of patients lost to follow up at the time of their statistical evaluation. The diagnosis of $\mathrm{CSH}$ had to be confirmed by computed tomography (CT) scans and/or magnetic resonance (MR) images in all patients prior to surgery. Studies had to identify burr hole craniostomy (single or double) as the first surgical treatment and indicate the number of burr holes performed in each patient as treatment for CSH. Only articles that compared the revision rate of $\mathrm{CSH}$ after single and double burr holes craniostomy for adult patients ( $>16$ years old) were included.

\section{Study quality assessment}

As all the studies in our systematic review were observational retrospective cohort studies, we used the Newcastle - Ottawa Quality Assessment Scale for cohort studies as our quality assessment tool. This validated scale evaluates cohort studies based on three characteristics: selection of the study groups, comparability between the groups and outcome of interest.

We considered a study with score of seven or more (on a scale of nine) to be of good quality. All studies in our systematic review appeared to be of good quality.

\section{Statistical analysis}

Data were processed in Review Manager 5.0.18 as supplied by Cochrane Collaboration; Oxford, UK. The statistical analysis for dichotomous variables was carried out using odds ratios (ORs) as the summary statistic; statistical significance was set at $\mathrm{P}$ value $<0.05$ or a $95 \%$ confidence interval $(\mathrm{CI})$ of odds ratio (OR) not including 1. Effect sizes were expressed in (pooled) odds ratio (OR) estimates. Pooled data were interpreted to be heterogeneous if the probability value of the $\chi^{2}$ test was $\leq 0.10$

\section{RESULTS}

The literature search did not identify any randomized control studies comparing the revision rate of $\mathrm{CSH}$ after SBHC and DBHC.

Five observational (retrospective cohort studies) were identified, four published and one unpublished study of one of the authors (G.P.), describing the outcomes of 355 double burr hole craniostomies and 358 single burr hole craniostomies to evacuate $713 \mathrm{CSH}$ in 631 patients.

Ninety-five percent confidence intervals and odds ratio for each individual study are summarized in a forest plot (Figure 1). 


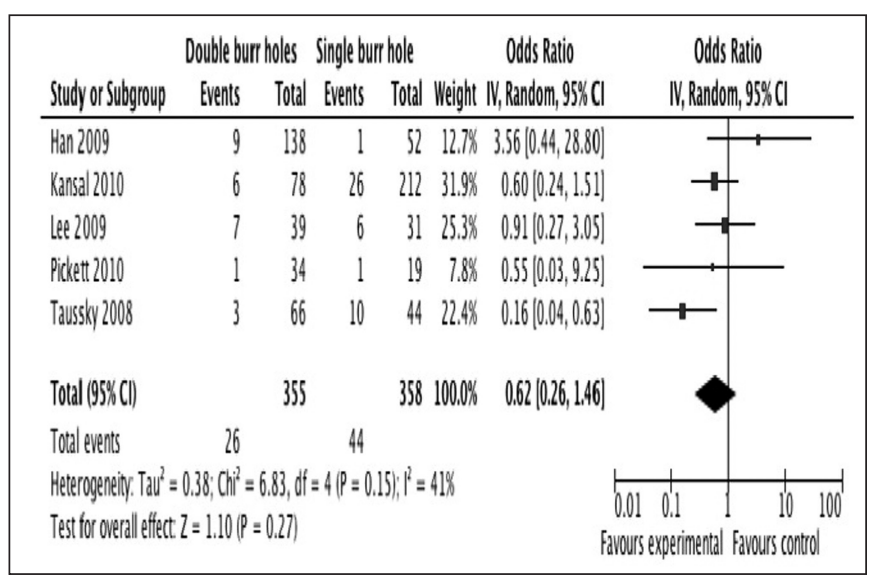

Figure 1: Summary of the data and odds ratio for each study individually and combined results with forest plot. For each study the number of patients who had single or double burr hole craniostomies is shown as (total) and number of patients who had recurrence of CSH is shown as (events) for each modality of treatment (single burr hole or double burr holes craniostomies). Weight of results of each study in the combined results is also shown.

All studies individually showed that there was no significant difference in revision rates between single versus double burr hole craniostomies in treating CSH, except the study by Taussky et al. ${ }^{4}$ which concluded that treatment of $\mathrm{CSH}$ with single burr hole is associated with significant higher postoperative revision rate. However, most studies had relatively low numbers of patients.

\section{Meta-analysis}

$\chi^{2}$ (for the pooled data) is 8.57 ; P-value for $\chi^{2}$ of 8.57 with degree of freedom $=4$ is 0.072 which is above our predetermined level of significance (0.05). This indicated that the studies are heterogeneous, and therefore we used random effect of the inverse variance weighted method to complete the meta-analysis of this review (Figure 1).

The combined odds ratio for all the studies was $0.62(95 \% \mathrm{CI}$ $0.26-1.46$ ), and the $\mathrm{Z}$ score of the combined odds ratio of revision of $\mathrm{CSH}$ for all the studies was $1.06(\mathrm{P}=0.27)$.

Since the $95 \%$ confidence interval of the combined odds ratio of the revision of CSH for all studies included one, and the Pvalue of the combined $\mathrm{Z}$ score for the combined odd ratio did not reach significance $(0.05)$, we concluded that there is no statistically significant difference in the revision rates after double burr holes craniostomy versus single burr hole craniostomy when performed to evacuate $\mathrm{CSH}$. This metaanalysis supports the hypothesis that, in terms of recurrence requiring revision, single burr hole craniostomy is as good as double burr hole craniostomy in treating $\mathrm{CSH}$.

\section{Sensitivity analysis}

We performed sensitivity analysis to test the results under varied conditions. We used the jackknife method to perform sensitivity analysis: as we have five studies in our review, we repeated the meta-analysis five times, each omitting a different study. The same result, i.e. P $>0.05$ and a $95 \% \mathrm{CI}$ that included the neutral value 1 , was obtained in all five conditions, indicating no significant difference in the revision rates between single and double burr holes craniostomies.

\section{Assessment of different types of biases}

To test whether publication bias was present among studies included in the meta-analysis, a funnel plot was undertaken (Figure 2.) Even though the total number of studies in this metaanalysis is only five, its distribution in the funnel plot is almost symmetrical suggesting no publication bias.

All studies included in this meta-analysis were retrospective cohort studies. They used the same design, diagnostic imaging of $\mathrm{CSH}$, indications for surgical treatment and ascertainment criteria for the recurrence of $\mathrm{CSH}$.

Recall bias was not a factor in these studies, even though they were retrospective studies, as in all cases the diagnosis of CSH was confirmed by imaging while surgical procedures and outcomes were identified by searching the surgical records for each patient.

Attrition bias or bias due to loss to follow-up is unlikely, as recurrence of CSH often occurs soon after surgery, prior to patient discharge home. Furthermore, clinical follow-up data from post-operative visits, provided in all studies, indicated no loss to follow-up.

\section{DISCUSSION}

To our knowledge, there has been no previous meta-analysis comparing the revision rates of single burr hole craniostomy (SBHC) versus double burr hole craniostomy (DBHC) to treat $\mathrm{CSH}$. It has been in the last three decades that burr hole craniostomy was widely considered to be the first line treatment for chronic subdural hematoma ${ }^{12}$, and still there is controversy

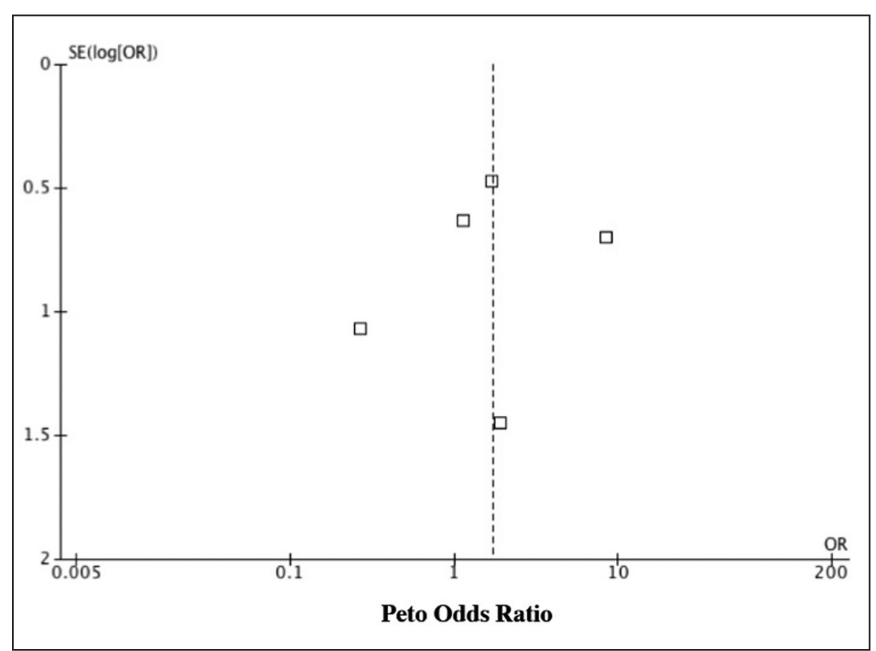

Figure 2: Funnel plot shows distribution of studies according to their sizes and results. The five studies are distributed almost symmetrically. Absence of both corners of the funnel in this plot is due to the small number of studies in this meta-analysis. 
among neurosurgeons regarding the optimal number of burr holes to evacuate $\mathrm{CSH}$. At times $\mathrm{CSH}$ may be loculated, having multiple small collections within the subdural space, which led to the argument that treating $\mathrm{CSH}$ with two holes might more effectively evacuate the hematoma, reduce the risk of recurrence and ultimately protect patients from having another surgery for recurrent or residual CSH. The first study aimed at assessing that claim was published in $2008^{4}$; this might explain why only five studies were found through an extensive search of the literature, as it has only been over the last few years that investigators began directly comparing single and double burr hole craniostomy in terms of recurrence rate and length of operation, risk of wound infection and complications.

The initial study by Taussky et $\mathrm{al}^{4}$ assessed whether the number of burr holes performed is an independent predictor of postoperative recurrence. They concluded that treatment of $\mathrm{CSH}$ with one burr hole only is associated with a statistically significant higher postoperative recurrence rate as compared with double burr hole craniostomy. However, subsequent studies published $^{2,3,11}$ did not show the same results, concluding that the number of burr holes used to evacuate $\mathrm{CSH}$ was not statistically associated with postoperative recurrence rate. There was no mention of loss to follow up in the studies of this review as patients who required revisions to re-evacuate the CSH often will not show symptomatic improvement and they would not be discharged from the hospital before they have another operation to re-evacuate the $\mathrm{CSH}$.
Limitations of this meta-analysis are that all studies were observational retrospective cohort studies and there was no randomization, matching or pairing between two patients groups of each individual study, so confounders such as thickness of the $\mathrm{CSH}$, use of anticoagulation by the patients, alcohol use, comorbidities and age of the patients between studies' groups were not controlled. However, some of the studies in this review did look at different confounders and found no difference between the groups (Table).

Another limitation is heterogeneity in the adjunct treatment intra- and post-operatively between studies. Kansal et $\mathrm{al}^{2}$ used a lot of irrigation during the procedure for both study groups and did not place any drain after the surgical procedure. Taussky et $\mathrm{al}^{4}$ also used irrigation intra-operatively for both study groups, but left a subdural drain in postoperatively for all patients; in contrast, Han et $\mathrm{al}^{11}$ used irrigation intra-operatively for the group of CSH treated with DBHC, and no irrigation for patients treated with SBHC, but placed a drain in all patients. Lee et $\mathrm{al}^{3}$ used irrigation for the group treated with DBHC but only some of the patients treated with SBHC and put drains in all patients, while with Pickett et al. all patients had irrigation intraoperatively but there was no uniformity in using drain postoperatively.

Given this heterogeneity in inserting subdural drain post evacuation of CSH between studies of this meta-analysis, it is worth mentioning that a randomized control study by Santarius et $\mathrm{al}^{13}$ showed that use of drain after burr hole drainage of $\mathrm{CSH}$

Table: Summary of studies included in meta-analysis

\begin{tabular}{|c|c|c|c|c|c|c|c|c|c|c|}
\hline \multirow{2}{*}{$\begin{array}{l}\text { Study } \\
\text { Procedure }\end{array}$} & \multicolumn{2}{|c|}{ Taussky et al (5) } & \multicolumn{2}{|c|}{ Han et $\mathrm{al}_{(1)}$} & \multicolumn{2}{|c|}{ Kansal et al.(3) $_{\text {. }}$} & \multicolumn{2}{|l|}{ Lee et al.(4) } & \multicolumn{2}{|l|}{ Pickett } \\
\hline & SBHC & DBHC & SBHC & DBHC & SBHC & $\mathrm{DBHC}$ & SBHC & DBHC & SBHC & DBHC \\
\hline $\begin{array}{l}\text { Number of } \\
\text { patients }\end{array}$ & 34 & 63 & 51 & 129 & 195 & 72 & 25 & 32 & 18 & 33 \\
\hline $\begin{array}{l}\text { Number of } \\
\text { patients who } \\
\text { had revision } \\
\text { operation }\end{array}$ & $10 / 34$ & $3 / 63$ & $1 / 51$ & $9 / 129$ & $26 / 195$ & $6 / 72$ & $6 / 25$ & $7 / 32$ & $1 / 18$ & $1 / 33$ \\
\hline $\begin{array}{l}\text { Mean age of } \\
\text { the patients in } \\
\text { each group }\end{array}$ & $\begin{array}{l}70+/- \\
12.6 \\
\text { years }\end{array}$ & $\begin{array}{l}69+/- \\
11.6 \\
\text { years }\end{array}$ & $\begin{array}{l}62.73 \\
+/- \\
13.73 \\
\text { years }\end{array}$ & $\begin{array}{l}62.2 \\
+/- \\
15.7 \\
\text { years }\end{array}$ & \multicolumn{2}{|c|}{$\begin{array}{l}\text { Mean age for both groups } \\
78+/-3 \text { years }\end{array}$} & $\begin{array}{l}62.28+/- \\
14.3 \text { years }\end{array}$ & $\begin{array}{l}65.31+/- \\
12.12 \text { years }\end{array}$ & \multicolumn{2}{|c|}{$\begin{array}{l}\text { Mean age for both groups } \\
72.1+/-13.9\end{array}$} \\
\hline $\begin{array}{l}\text { Mean of initial } \\
\text { maximum } \\
\text { thickness of } \\
\text { CSH }\end{array}$ & $\begin{array}{l}1.8 \\
+/- \\
0.7 \\
\mathrm{~cm}\end{array}$ & $\begin{array}{l}1.85 \\
+/-0.8 \\
\mathrm{~cm}\end{array}$ & $\begin{array}{l}1.8 \\
+/- \\
0.6 \\
\mathrm{~cm}\end{array}$ & $\begin{array}{l}1.91 \\
+/- \\
0.74 \\
\mathrm{~cm}\end{array}$ & \multicolumn{2}{|c|}{$\begin{array}{l}\text { It was mentioned that the } \\
\text { thickness of CSH is comparable } \\
\text { between the two groups but } \\
\text { number were not provided }\end{array}$} & $\begin{array}{l}2131.50+/- \\
1117.78 \\
\mathrm{~mm}^{2}\end{array}$ & $\begin{array}{l}2052.12+/- \\
1280.92 \\
\mathrm{~mm}^{2}\end{array}$ & \multicolumn{2}{|c|}{$\begin{array}{l}\text { It was mentioned that the } \\
\text { thickness of CSH is comparable } \\
\text { between the two groups but } \\
\text { number were not provided }\end{array}$} \\
\hline $\begin{array}{l}\text { Number of } \\
\text { patients who } \\
\text { were on } \\
\text { anticoagulation } \\
\text { prior to the } \\
\text { operation in } \\
\text { each group }\end{array}$ & $23 / 34$ & $30 / 63$ & \multicolumn{2}{|c|}{ Not available } & \multicolumn{2}{|c|}{$\begin{array}{l}\text { Patients who were on } \\
\text { anticoagulation therapy was } \\
\text { excluded from the study }\end{array}$} & \multicolumn{2}{|l|}{ Not available } & \multicolumn{2}{|c|}{$\begin{array}{l}18 \text { out of } 51 \text { patients of this } \\
\text { study were receiving } \\
\text { anticoagulation therapy prior to } \\
\text { the operation, but it was not } \\
\text { specified in which group they } \\
\text { were located. }\end{array}$} \\
\hline $\begin{array}{l}\text { Mean of the } \\
\text { Glasgow coma } \\
\text { scale of the } \\
\text { patients in } \\
\text { each group } \\
\text { prior to the } \\
\text { operation }\end{array}$ & $\begin{array}{l}14+/- \\
1\end{array}$ & $\begin{array}{l}14+/- \\
1\end{array}$ & $\begin{array}{l}12.4 \\
+/- \\
1.3\end{array}$ & $\begin{array}{l}12.6 \\
+/-1.3\end{array}$ & Not ave & & $\begin{array}{l}\text { Markwalder } \\
\text { score was } \\
\text { reported } \\
1.44+/- \\
0.58\end{array}$ & $\begin{array}{l}\text { Markwalder } \\
\text { score was } \\
\text { reported } \\
1.34+/- \\
0.55\end{array}$ & $13.5+/-1$ & $13.5+/-1$ \\
\hline
\end{tabular}

SBHC: Single Burr hole Craniostomy; DBHC: Double Burr hole Craniostomy 
is safe and associated with reduced recurrence and mortality at six months.

Despite the limitations described, we believe the results of our meta-analysis are currently the best available evidence regarding revision rates between $\mathrm{SBHC}$ and $\mathrm{DBHC}$ when performed to treat adult patients with $\mathrm{CSH}$.

\section{Conclusion}

Meta-analysis of the available literature that compared the revision rates after $\mathrm{SBHC}$ versus $\mathrm{DBHC}$ in treatment of $\mathrm{CSH}$ showed no significant difference between the two procedures. A randomized controlled trial would be required to control for all confounders and confirm this conclusion. There may, however, be little support for such a trial in the neurosurgical world, given the good outcomes and relatively low recurrence risk achieved with any of the surgical treatments for CSH.

\section{Disclosures}

One of the authors of this systematic review is the author of an unpublished study that is included in the review (GP).

\section{REFERENCES}

1. Weigel R, Schmiedek P, Krauss JK. Outcome of contemporary surgery for chronic subdural haematoma: evidence based review. J NeurolNeurosurg Psychiatry. 2003 Jul;74(7):937-43.

2. Kansal R, Nadkarni T, Goel A. Single versus double burr hole drainage of chronic subdural hematomas. A study of 267 cases. J ClinNeurosci. 2010 Apr;17(4):428-9.

3. Lee JK, Choi JH, Kim CH, Lee HK, Moon JG. Chronic subdural hematomas : a comparative study of three types of operative procedures. J Korean Neurosurg Soc. 2009 Sep;46(3):210-14.

4. Taussky P, Fandino J, Landolt H. Number of burr holes as independent predictor of postoperative recurrence in chronic subdural haematoma. Br J Neurosurg. 2008 Apr;22(2):279-82.

5. Vignes JR. Surgical treatment of chronic subdural hematoma in the adult. Review of the literature. Neurochirurgie. 2001 Nov;47(5): 479-87.

6. Gelabert-Gonzalez M, Iglesias-Pais M, Garcia-Allut A, MartinezRumbo R. Chronic subdural haematoma: surgical treatment and outcome in 1000 cases. Clin Neurol Neurosurg. 2005;107(3): 223-9.

7. Cenic A, Bhandari M, Reddy K. Management of chronic subdural hematoma: a national survey and literature review. Can J Neurol Sci. 2005 Nov;32(4):501-6.

8. Rohde V, Graf G, Hassler W. Complications of burr-hole craniostomy and closed-system drainage for chronic subdural hematomas: a retrospective analysis of 376 patients. Neurosurg Rev. 2002 Mar;25(1-2):89-94.

9. Okada Y, Akai T, Okamoto K, Iida T, Takata H, Iizuka H. A comparative study of the treatment of chronic subdural hematoma-burr hole drainage versus burr hole irrigation. Surg Neurol. 2002 Jun;57(6):405-9; discussion 410.

10. Lega BC, Danish SF, Malhotra NR, Sonnad SS, Stein SC. Choosing the best operation for chronic subdural hematoma: a decision analysis. J Neurosurg. 2010 Sep;113(3):615-21.

11. Han HJ, Park CW, Kim EY, Yoo CJ, Kim YB, Kim WK. One vs. two burr hole craniostomy in surgical treatment of chronic subdural hematoma. J Korean Neurosurg Soc. 2009 Aug;46(2): 87-92.

12. Oishi M, Toyama M, Tamatani S, Kitazawa T, Saito M. Clinical factors of recurrent chronic subdural hematoma. Neurol Med Chir. 2001 Aug;41(8):382-6.

13. Santarius T, Kirkpatrick PJ, Ganesan D, Chia HL, Jalloh I, Smielewski P. Use of drains versus no drains after burr-hole evacuation of chronic subdural haematoma: a randomised controlled trial. Lancet. 2009;374:1067-73. 